\title{
Vibrational Spectroscopic and Computational Studies on Bis(2-aminopyridinium)fumarate - Fumaric Acid (1:1) Complex
}

\author{
N. Kanagathara ${ }^{a, *}$ K. PAWlus $^{b}$ And M.K. MARChewKA ${ }^{b}$ \\ ${ }^{a}$ Department of Physics, Saveetha School of Engineering, Saveetha Institute of Medical and Technical Sciences, \\ Thandalum, Chennai 602 105, India \\ ${ }^{b}$ Institute of Low Temperature and Structure Research, Polish Academy of Sciences, 50-950 Wrocław 2, Poland
}

(Received October 15, 201\%; in final form November 15, 2017)

The new vibrational and computational studies on bis(2-aminopiridinium) fumarate — fumaric acid (1:1) complex have been made. The molecular geometry, vibrational frequencies and intensities of vibrational bands have been interpreted with the aid of structure optimization based on density functional theory (B3LYP) method with $6-311++\mathrm{G}(\mathrm{d}, \mathrm{p})$ basis set. The highly occupied-lowly unoccupied molecular orbital energies and chemical reactivity of the molecule have been calculated with time-dependent density functional theory approach. Stability energies of the molecule have been studied using natural bond orbital analysis. The predicted nonlinear optical properties of the title compound are much greater that those of urea. In addition, the molecular electrostatic potential surfaces and thermodynamic properties were calculated.

DOI: 10.12693/APhysPolA.133.45

PACS/topics: 2-aminopyridine, fumaric acid, DFT, FT-IR, FT-Raman

\section{Introduction}

The crystal structure of 2-aminopyrimidine-fumaric acid co-crystal was published by Goswami et al. [1] with the unit cell parameters $a=3.80, b=19.18$, $c=13.06 \AA$ and $\beta=96.89^{\circ}$. Later the crystal structure of the bis(2-aminopyridinium) fumarate - fumaric acid (1:1) (2APF-F) was published and deposited in the CSD database in 2002 by Ballabh et al. [2] and found that the compound crystallized in monoclinic system with $P 2_{1} / c$ space group, the unit cell parameters are as follows: $a=10.47, b=4.95 \AA, c=19.21 \AA$ and $\beta=102.14^{\circ}$. The carboxylate group of the $2 \mathrm{APF}-\mathrm{F}$ interacts with the aminopyridinium cation through the pair of $\mathrm{N}-\mathrm{H} . . . \mathrm{O}$ hydrogen bonds and form an eightmembered $R_{2}^{2}$ (8) ring motif. This motif is one of the 24 most frequently observed bimolecular cyclic hydrogenbonded motifs in organic crystal structures. In 2013 Dong et al. [3] found the new polymorph of 2APF-F, which crystallized in triclinic system in centrosymmetric space group. In both polymorphs asymmetric units consist of one 2-aminopirydinium cation, half a fumaric acid molecule and half a fumarate dianion.

The fumaric acid is an organic dicarboxylic acid which is widely found in nature and it is also a key intermediate in the biosynthesis of organic acids. The fumaric and maleic acid are the simplest dicarboxylic acids exhibiting a carbon-carbon double bond. Both acids have important applications in polymer industry $[4,5]$ and also in medicine [6-9] as anti-fungicides and antitumor agents. Macoas et al. studied the spectroscopic and computa-

*corresponding author; e-mail: kanagathara23275@gmail.com tional studies of $(E)$ - and $(Z)$-buthenedioic acids [10]. The heteroaromatic pharmaceuticals containing nitrogen (like pyridine) are very popular in the resent days. The aminopyridine molecules are mainly used as the starting materials in the production of various drugs. The aminopyridine and derivatives are used in the synthesis of pharmaceuticals especially for antihistamines, antiinflammatories drugs. The Fourier transform infrared (FT-IR) and the Raman spectra of pure 2-aminopyridine were studied by Mohan and Ilangovan [11]. The fumaric acid and 2-aminopyridine could be proton donor and/or acceptor and are widely used in crystal engineering to obtain the structures with rich hydrogen bonds network. The excellent hydrogen bond network in this combination makes it suitable for NLO applications [12]. The weak intermolecular interactions, like hydrogen bonds cause significant changes in the vibrational spectra [13]. In addition in the crystals are symmetrically spread molecules which can cause some kinds of splitting [14]. These effects make the spectra of the solids differ from spectra of liquids or gases. It is known that vibrational (IR and Raman) spectroscopy would be a suitable method to study hydrogen-bonded complexes in crystalline form.

In this communication, the detailed assignment of vibrational studies of 2APF-F is discussed by both theoretical and experimental results. Density functional theory (DFT) calculations are used in order to perform structural analysis of the title molecule. Additionally, the non-linear optical properties, frontier orbitals, molecular electrostatic potential, interaction energies (NBO) and statistical thermodynamic properties have been investigated using B3LYP method.

\section{Experimental}

The starting compounds, 2-aminopyridine (Merck, $\geq 98 \%$ ) and fumaric acid (Merck, $\geq 99 \%$ ), were used with- 
out any further purification. Compounds were dissolved in doubly distilled water in equimolar amounts. Then the solution was purified with the aid of charcoal and allowed to evaporate at room temperature. Crystals of bis(2-aminopyridine) fumarate - fumaric acid (1:1) appeared after a month.

\section{Characterization}

The X-ray diffraction data were collected on a four circle KUMA KM-4 diffractometer equipped with a twodimensional area CCD detector. The graphite monochromatized Mo $K_{\alpha}(\lambda=0.71073 \AA)$ and $\omega$-scan technique with $\Delta \omega=0.75^{\circ}$ for one image were used for data collection. Integration of the intensities, correction for Lorentz and polarization effects was performed using KUMA KM-4 CCD software [15]. The crystal structure was solved by a direct method and subsequent difference Fourier syntheses of SHELXL-PLUS program system [16] and the structure was refine by use of SHELXL 97 [17]. Anisotropic displacement parameters were included for all non-hydrogen atoms. The spectroscopic measurements were carried out at room temperature, in the region $4000-80 \mathrm{~cm}^{-1}$. The powder infrared spectra were measured using Bruker IFS- 88 spectrometer with resolution $2 \mathrm{~cm}^{-1}$, signal/noise ratio were established by 32 scans. The samples in Nujol and Fluorolube suspensions were used to eliminate the bands originating from the oils. Powder Fourier transform Raman spectra were taken with an FRA-106 attachment to the Bruker IFS88 spectrometer equipped with Ge detector cooled to liquid nitrogen temperature. $\mathrm{Nd}^{+3}$ :YAG air-cooled diode pumped laser of power ca. $500 \mathrm{~mW}$ was used as an excitation source. The incident laser excitation was $1064 \mathrm{~nm}$. The scattered light was collected at the angle $180^{\circ}$ in the region $3600-80 \mathrm{~cm}^{-1}$, resolution $2 \mathrm{~cm}^{-1}, 32$ scans.

\section{Computation details}

The DFT has long been recognized as a better alternative tool in the study of organic, inorganic chemical system. In the present study, DFT calculations were performed by DFT-B3LYP method with 6-311++G(d,p) basis set using Gaussian 09 program [18], under the calculation grant at WCSS (WCSS\#106602). The single crystal X-ray diffraction experimental results are given as input to the Gaussian program to obtain the molecular geometry. Vibrational frequencies were scaled by 0.9613 [19]. The assignment of the calculated normal modes has been made on the basis of the corresponding PEDs. The PEDs are computed with quantum mechanically calculated vibrational frequencies using VEDA program [20]. The energy gap value between the highest occupied molecular orbital (HOMO) and lowest unoccupied molecular orbital (LUMO) energies was also calculated. The chemical reactivity was also calculated by IEF-PCM method in one solvent-water $(\varepsilon=78.39)$. Electrostatic potential energy surface map is employed to convey the varying intensities of the electrostatic potential energy values. The polarizability $\alpha$, dipole moment $\mu$ and first order hyperpolarizability $\beta$ are calculated using B3LYP $/ 6-311++\mathrm{G}(\mathrm{d}, \mathrm{p})$ basis set on the basis of the finite-field approach. The NBO analysis was performed at the B3LYP $/ 6-311++\mathrm{G}(\mathrm{d}, \mathrm{p})$ level of theory by means of the NBO 3.1 [21] program within the Gaussian 09 package.

\section{Results and discussion}

\subsection{Structural analysis}

The obtained crystal crystallizes in the monoclinic system with $P 2_{1} / c$ space group. The lattice constants are: $a=10.387(18) \AA, b=4.926(10), c=19.148(19), \alpha=$ $\gamma=90^{\circ}, \beta=101.61(10)^{\circ}$. Other crystallographic parameters are collected in Table I. Atoms numbering scheme is

Crystallographic data of 2APF-F crystal

TABLE I

\begin{tabular}{c|c|c|c}
\hline \hline & {$[10]$} & {$[11]$} & Exp. \\
\hline Formula & $\mathrm{C}_{9} \mathrm{H}_{10} \mathrm{~N}_{2} \mathrm{O}_{4}$ & $\mathrm{C}_{18} \mathrm{H}_{20} \mathrm{~N}_{4} \mathrm{O}_{8}$ & $\mathrm{C}_{9} \mathrm{H}_{10} \mathrm{~N}_{2} \mathrm{O}_{4}$ \\
\hline $\mathrm{M}$ & 210.19 & 420.38 & 210.19 \\
\hline crystal system & monoclinic & triclinic & monoclinic \\
\hline space group & $P 2_{1} / c$ & $P-1$ & $P 2_{1} / c$ \\
\hline$a[\AA]$ & $10.467(3)$ & $3.816(7)$ & $10.387(18)$ \\
\hline$b[\AA]$ & $4.947(2)$ & $9.606(3)$ & $4.926(10)$ \\
\hline$c[\AA]$ & $19.211(3)$ & $13.360(4)$ & $19.148(19)$ \\
\hline$\alpha\left[^{\circ}\right]$ & 90 & $94.287(15)$ & 90 \\
\hline$\beta\left[{ }^{\circ}\right]$ & 102.14 & $91.743(14)$ & $101.61(10)$ \\
\hline$\gamma\left[^{\circ}\right]$ & 90 & $91.716(14)$ & 90 \\
\hline$V\left[\AA^{3}\right]$ & $972.5(5)$ & $488.02(3)$ & $957.5(2)$ \\
\hline$Z$ & 4 & 1 & 4 \\
\hline$T[\mathrm{~K}]$ & 293 & 298 & $210(2)$
\end{tabular}
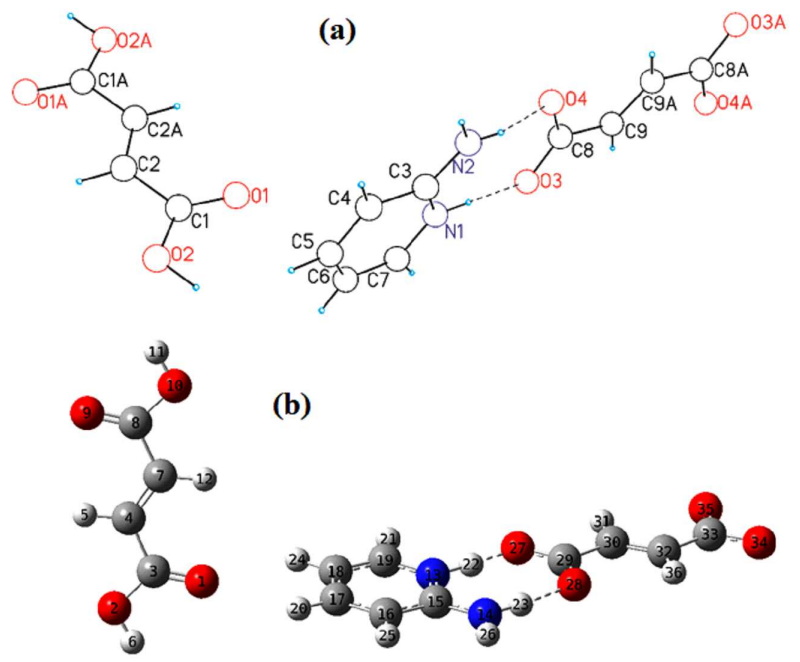

Fig. 1. Molecular structure of 2APF-F: (a) experimental (b) theoretical. 
Selected molecular structure parameters.

TABLE II

\begin{tabular}{|c|c|c|}
\hline & Exp. [1] & B3LYP $/ 6-311++\mathrm{G}(\mathrm{d} \cdot \mathrm{p})$ \\
\hline \multicolumn{3}{|c|}{ Bond length $[\AA]$} \\
\hline $\mathrm{O} 3-\mathrm{C} 8$ & $1.271(2)$ & 1.272 \\
\hline $\mathrm{C} 8-\mathrm{O} 4$ & $1.249(2)$ & 1.250 \\
\hline $\mathrm{C} 8-\mathrm{C} 9$ & $1.497(2)$ & 1.506 \\
\hline $\mathrm{C} 9-\mathrm{H} 10$ & $0.94(2)$ & 1.085 \\
\hline $\mathrm{C} 9-\mathrm{C} 9 \mathrm{~B}$ & $1.315(2)$ & 1.335 \\
\hline $\mathrm{H} 2-\mathrm{O} 2$ & $1.04(3)$ & 1.083 \\
\hline $\mathrm{O} 2-\mathrm{C} 1$ & $1.314(2)$ & 1.342 \\
\hline $\mathrm{C} 1-\mathrm{O} 1$ & $1.210(2)$ & 1.210 \\
\hline $\mathrm{C} 1-\mathrm{C} 2$ & $1.492(2)$ & 1.483 \\
\hline $\mathrm{C} 2-\mathrm{H} 1$ & $0.95(2)$ & 0.969 \\
\hline $\mathrm{C} 2-\mathrm{C} 2 \mathrm{~B}$ & $1.303(2)$ & 1.333 \\
\hline H9-N2 & $0.92(2)$ & 1.005 \\
\hline $\mathrm{H} 6-\mathrm{N} 2$ & $0.89(2)$ & 1.044 \\
\hline $\mathrm{N} 2-\mathrm{C} 3$ & $1.328(2)$ & 1.338 \\
\hline $\mathrm{N} 1-\mathrm{H} 5$ & $0.93(2)$ & 1.114 \\
\hline $\mathrm{C} 7-\mathrm{N} 1$ & $1.361(2)$ & 1.352 \\
\hline $\mathrm{N} 1-\mathrm{C} 3$ & $1.353(2)$ & 1.357 \\
\hline $\mathrm{C} 7-\mathrm{C} 6$ & $1.354(3)$ & 1.370 \\
\hline $\mathrm{C} 6-\mathrm{C} 5$ & $1.399(3)$ & 1.409 \\
\hline $\mathrm{C} 5-\mathrm{C} 4$ & $1.358(3)$ & 1.374 \\
\hline $\mathrm{C} 3-\mathrm{C} 4$ & $1.415(2)$ & 1.419 \\
\hline $\mathrm{C} 7-\mathrm{H} 4$ & $1.02(2)$ & 1.082 \\
\hline $\mathrm{C} 6-\mathrm{H} 7$ & $0.94(2)$ & 1.080 \\
\hline C5-H3 & $0.95(2)$ & 1.083 \\
\hline $\mathrm{C} 4-\mathrm{H} 8$ & $0.98(2)$ & 1.082 \\
\hline \multicolumn{3}{|c|}{ Max. difference $^{a}[\AA] \quad 0.184 \mathrm{~N} 1-\mathrm{H} 5$} \\
\hline \multicolumn{3}{|c|}{ Bond angles $\left[{ }^{\circ} \mathrm{C}\right]$} \\
\hline $\mathrm{O} 3-\mathrm{C} 8-\mathrm{O} 4$ & $123.5(1)$ & 126.35 \\
\hline $\mathrm{O} 4-\mathrm{C} 8-\mathrm{C} 9$ & $118.9(1)$ & 118.76 \\
\hline $\mathrm{C} 8-\mathrm{C} 9-\mathrm{C} 9 \mathrm{~B}$ & $123.6(1)$ & 122.29 \\
\hline $\mathrm{H} 10-\mathrm{C} 9-\mathrm{C} 8$ & $115(1)$ & 116.40 \\
\hline $\mathrm{H} 2-\mathrm{O} 2-\mathrm{C} 1$ & $114(2)$ & 107.90 \\
\hline $\mathrm{O} 2-\mathrm{C} 1-\mathrm{O} 1$ & $124.7(1)$ & 123.04 \\
\hline $\mathrm{C} 1-\mathrm{C} 2-\mathrm{C} 2 \mathrm{~A}$ & $123(2)$ & 120.94 \\
\hline $\mathrm{H} 1-\mathrm{C} 2-\mathrm{C} 1$ & $115(1)$ & 118.00 \\
\hline $\mathrm{H} 6-\mathrm{N} 2-\mathrm{H} 9$ & $123(2)$ & 119.66 \\
\hline $\mathrm{H} 9-\mathrm{N} 2-\mathrm{C} 3$ & $118(1)$ & 119.08 \\
\hline $\mathrm{N} 2-\mathrm{C} 3-\mathrm{C} 4$ & $123.4(1)$ & 123.90 \\
\hline $\mathrm{N} 1-\mathrm{C} 3-\mathrm{C} 4$ & $117.4(1)$ & 118.01 \\
\hline $\mathrm{H} 8-\mathrm{C} 4-\mathrm{C} 5$ & $125(1)$ & 121.39 \\
\hline $\mathrm{C} 5-\mathrm{C} 4-\mathrm{C} 3$ & $120.1(2)$ & 119.75 \\
\hline
\end{tabular}

${ }^{a}$ Maximum differences between the bond lengths and angles computed using theoretical methods and those obtained from X-ray diffraction.

presented in Fig. 1a. The asymmetric unit cell of [2APF$\mathrm{F}$ ] contains one 2-aminopyridine cation, half of the fumarate dianion and half acid molecule - both are located in the centers of symmetry. The structure is stabilized by hydrogen bonding. Hydrogen bond in 2APF-F crystal structure is shown in Fig. 2. Crystal structure revealed that the dianion is involved in complementary dimeric hydrogen bonding interactions with two 2-aminopyridinium

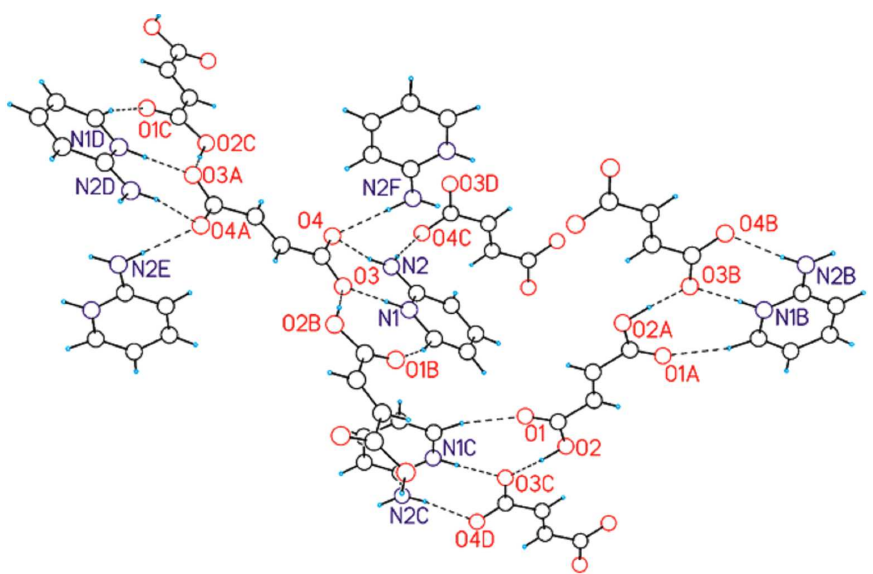

Fig. 2. Hydrogen bonds in 2APF-F crystal structure.

cations and such assemblies are held together by $\mathrm{N}-$ H. . . O hydrogen bonding in a staircase fashion. Dianions and the acid molecules form hydrogen bonds $\mathrm{O}-\mathrm{H}$... O thereby form chains extending along $a\left(C_{0}^{2}(6)\right.$ considering the dianion or $C_{2}^{0}(8)$ considering the free acid, graph set representation). The 2-aminopyridinium cations sit in between the chains through $\mathrm{N}-\mathrm{H}$. . O and $\mathrm{C}-\mathrm{H}$... O hydrogen bonds $\left(R_{2}^{3}(8)\right.$ and $R_{2}^{2}(8)$ graph set representation). In this way a $2 \mathrm{D}$ hydrogen bonded sheet along the $a c$-plane is made.

TABLE III

Hydrogen bonds of 2APF-F. $d[\AA], \angle\left[^{\circ}\right]$.

\begin{tabular}{c|c|c|c}
\hline \hline $\mathrm{D}-\mathrm{H} \cdots \mathrm{A}$ & $d(\mathrm{H} \cdots \mathrm{A})$ & $d(\mathrm{D} \cdots \mathrm{A})$ & $\angle(\mathrm{D}-\mathrm{H} \cdots \mathrm{A})$ \\
\hline $\mathrm{O} 2-\mathrm{H} 2 \cdots \mathrm{O} 3^{a}$ & 1.58 & 2.61 & 175.0 \\
$\mathrm{~N} 1-\mathrm{H} 5 \cdots \mathrm{O} 3$ & 1.84 & 2.77 & 174.8 \\
$\mathrm{~N} 2-\mathrm{H} 9 \cdots \mathrm{O} 4$ & 1.99 & 2.86 & 164.6 \\
$\mathrm{~N} 2-\mathrm{H} 6 \cdots 2^{b}$ & 2.03 & 2.94 & 166.0 \\
$\mathrm{C} 7-\mathrm{H} 4 \cdots 1^{c}$ & 2.18 & 3.18 & 167.8 \\
${ }^{a}:-x+1, y-0.5,-z+0.5 ;{ }^{b}:-x, y-0.5,-z+0.5 ;$ \\
${ }^{c}:-x+1, y+0.5,-z+0.5$
\end{tabular}

The optimized geometrical parameters of bis(2aminopyridine) fumarate - fumaric acid (1:1) are obtained using B3LYP $/ 6-311++\mathrm{G}(\mathrm{d}, \mathrm{p})$ method and the results are listed in Table II. The atomic numbering scheme of the theoretical molecular structure of the studied compound is shown in Fig. 1b. As seen from Table II, most of the bond lengths are insignificantly longer than the experimental values and the bond angles are slightly smaller from experimental ones. It should be noted that experimental results belong to solid phase and theoretical computations belong to the gas phase. The comparison reveals that there are no big differences between these two structures. Table III lists the hydrogen bonds of 2APF-F. The N-H. . O, O-H. . O and C-H. . O hydrogen bonds are formed between cations and dianions, dianions and fumaric acid molecules. In the optimized geometry only intramolecular hydrogen bonds are created between 2-aminopyridine cation and fumarate dianion. The biggest difference in bond lengths $\approx 0.184 \AA$ is found 
in $\mathrm{H} 5-\mathrm{N} 1$ bond between the experimental and the predicted value. The biggest difference for the bond angles is found as $6.1^{\circ}$ at $\mathrm{H} 2-\mathrm{O} 2-\mathrm{C} 1$. The biggest differences of bond lengths and bond angles mainly occur in the groups involved in the hydrogen bonds, which can be also easily understood by taking into account the intermolecular interactions present in the crystal.

\subsection{Vibrational analysis}

The optimized structural parameters were used to compute the vibrational frequencies of $2 \mathrm{APF}-\mathrm{F}$ by using B3LYP $/ 6-311++\mathrm{G}(\mathrm{d}, \mathrm{p})$ method. The experimental vibrational spectra for normal and deuterated crystals are shown in Figs. 3 and 4, respectively. The total num-

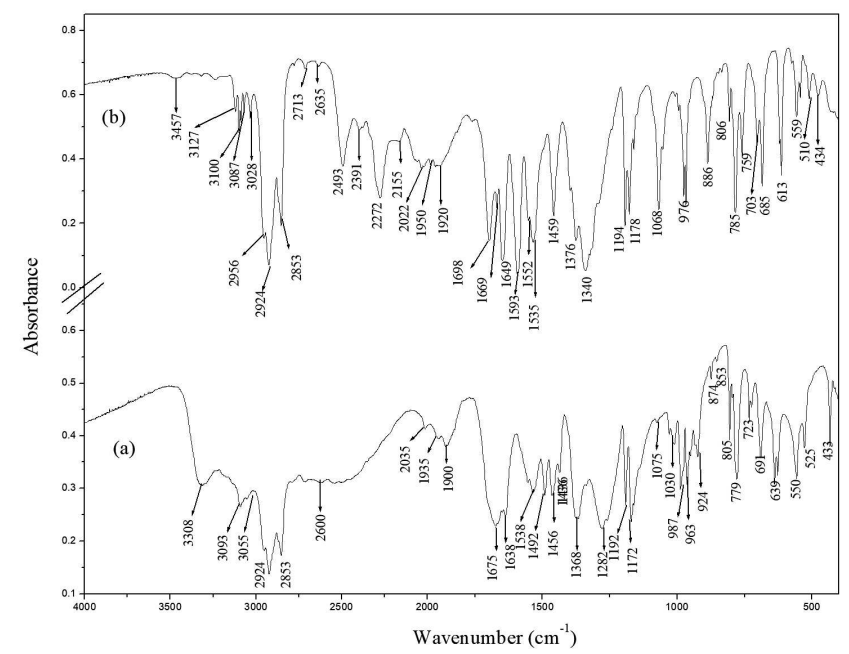

Fig. 3. Experimental (a) and deuterated analogue (b) FT-IR spectrum of $2 \mathrm{APF}-\mathrm{F}$.

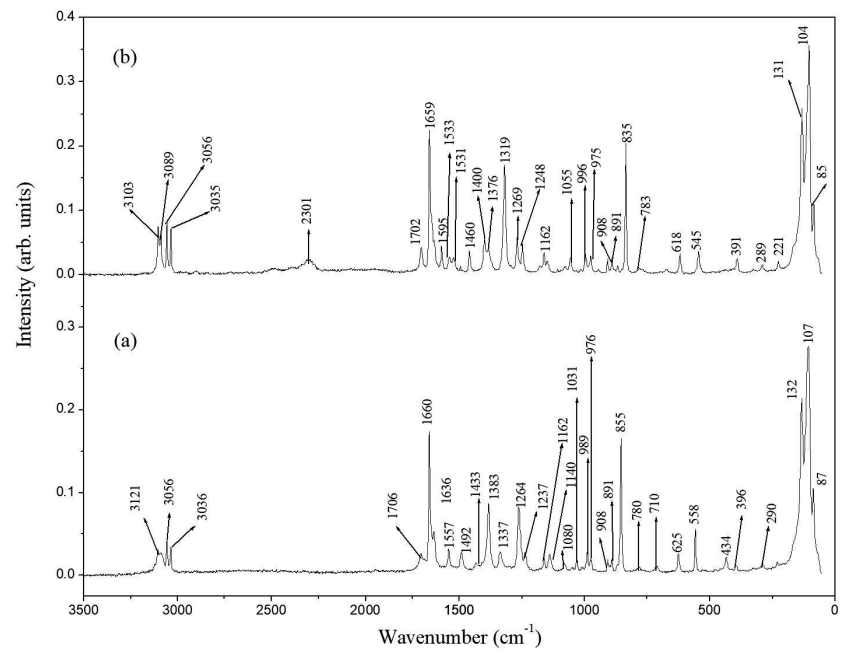

Fig. 4. Experimental (a) and deuterated analogue (b) FT-Raman spectrum of 2APF-F.

ber of vibrations of $2 \mathrm{APF}-\mathrm{F}$ consists of 96 external vibration (vibration of crystal lattice) and 504 internal vibrations. Table IV summarizes the internal and external vibrations. According to the selection rules, 252
TABLE IV

Fundamental external and internal vibrational analysis of $2 \mathrm{APF}-\mathrm{F}$.

\begin{tabular}{c|c|c|c|c|c|c|c|c}
\hline \hline \multirow{2}{*}{$C_{2 h}$} & \multicolumn{3}{|c|}{ Ext. } & \multicolumn{3}{c|}{ Int. } & \multicolumn{2}{c}{ Select. rules } \\
\cline { 2 - 9 } & $\mathrm{T}_{a}$ & $\mathrm{~T}$ & $\mathrm{R}$ & $\mathrm{D}$ & $\mathrm{C}$ & $\mathrm{A}$ & $\mathrm{IR}$ & Raman \\
\hline$A_{g}$ & & 12 & 12 & 24 & 72 & 30 & & $x x . y y . z z . x y$ \\
$B_{g}$ & & 12 & 12 & 24 & 72 & 30 & & $x z . y z$ \\
$A_{u}$ & 1 & 11 & 12 & 24 & 72 & 30 & $z$ & \\
$B_{u}$ & 2 & 10 & 12 & 24 & 72 & 30 & $x . y$ & \\
\hline
\end{tabular}

$\mathrm{T}_{a}$ - acoustic; $\mathrm{T}$ - translational; $\mathrm{R}$ - librations; $\mathrm{D}$ fumarate dianion $\mathrm{C}_{i} ; \mathrm{C}-2$-aminopyridine cation $\mathrm{C}_{1}$; $\mathrm{A}$ - fumaric acid $\mathrm{C}_{i}$.

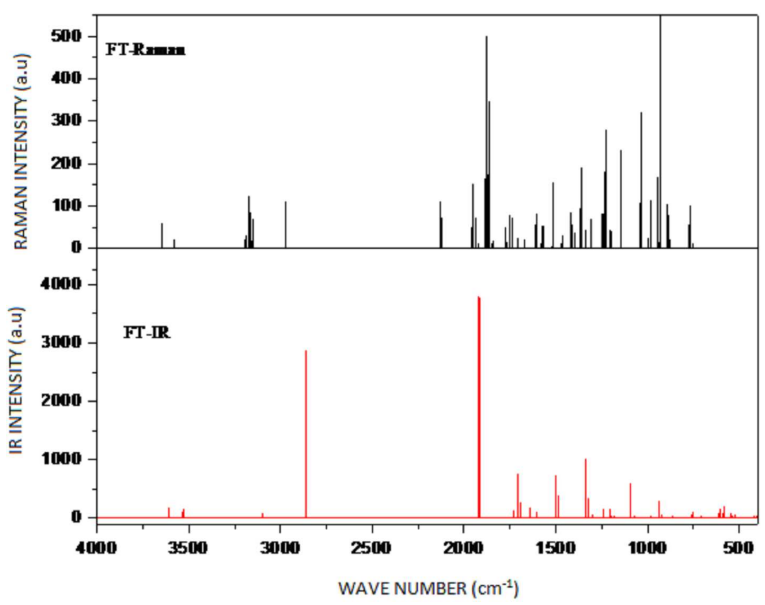

Fig. 5. Theoretical FT-IR and FT-Raman spectrum of 2APF-F.

internal vibrations should be observed in the IR spectrum and 252 on the Raman spectra. As shown on the IR and Raman spectra the number of vibration it is much smaller. This may be the result of applying vibrations of similar energies. The bands observed in the region $4000-200 \mathrm{~cm}^{-1}$ arise from the vibrations of protons in the hydrogen bonds, the internal vibrations of 2aminopyridine cations, fumarate anions and fumaric acid. The bands below $200 \mathrm{~cm}^{-1}$ arise from the lattice vibrations of the crystal. Theoretical FT-IR and FT Raman spectra (Fig. 5) are interpreted by means of PEDs using VEDA program [20]. The observed FTIR, FT-Raman and calculated frequencies determined by B3LYP method with $6-311++\mathrm{G}($ d.p) basis set along with relative intensities, probable assignments and potential energy distribution (PED) are listed in Table V. The Raman intensities derived from the computed Raman activities using the equation

$$
I_{i}^{R}=C\left(v_{0}-v_{i}\right)^{4} v_{i}^{-} 1 B_{i}^{-1} S_{i},
$$

where $v_{0}=9398.5 \mathrm{~cm}^{-1}(1064 \mathrm{~nm}), B_{i}=1-$ $\exp \left(-h v_{i} c / k T\right), v_{i}$ is the frequency of normal mode $\left[\mathrm{cm}^{-1}\right], S_{i}$ is the Raman activity of the normal mode, $h$ - the Planck constant $[\mathrm{eV} / \mathrm{s}], k$ - the Boltzmann constant $[\mathrm{eV} / \mathrm{K}], c$ - speed of light $[\mathrm{cm} / \mathrm{s}], T$ - temperature in $\mathrm{K}-298.15 \mathrm{~K}[22]$. 
TABLE V

The observed FTIR, FT-R(aman) $\left[\mathrm{cm}^{-1}\right]$ and calculated frequencies determined by B3LYP method with 6-311++G(d.p) basis set along with relative intensities. probable assignments and potential energy distribution (PED). A - bis $(2-$ aminopyridine) fumarate - fumaric acid (1:1), B - deutered bis(2-aminopyridine) fumarate — fumaric acid (1:1), $\mathrm{C}$ - scaled calculated wavenumbers [cm], D - IR intensity, E - Raman activity.

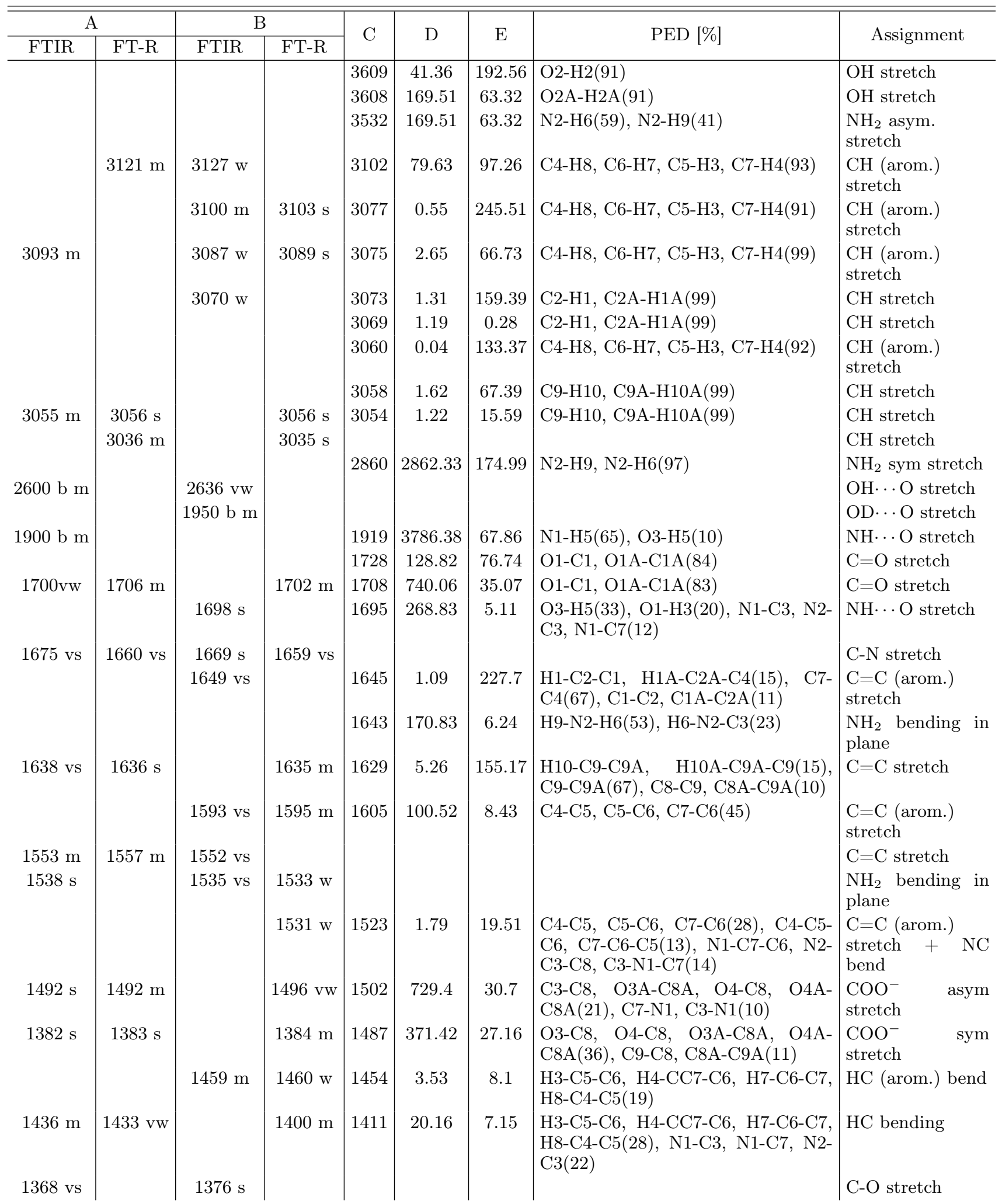


TABLE V (cont.)

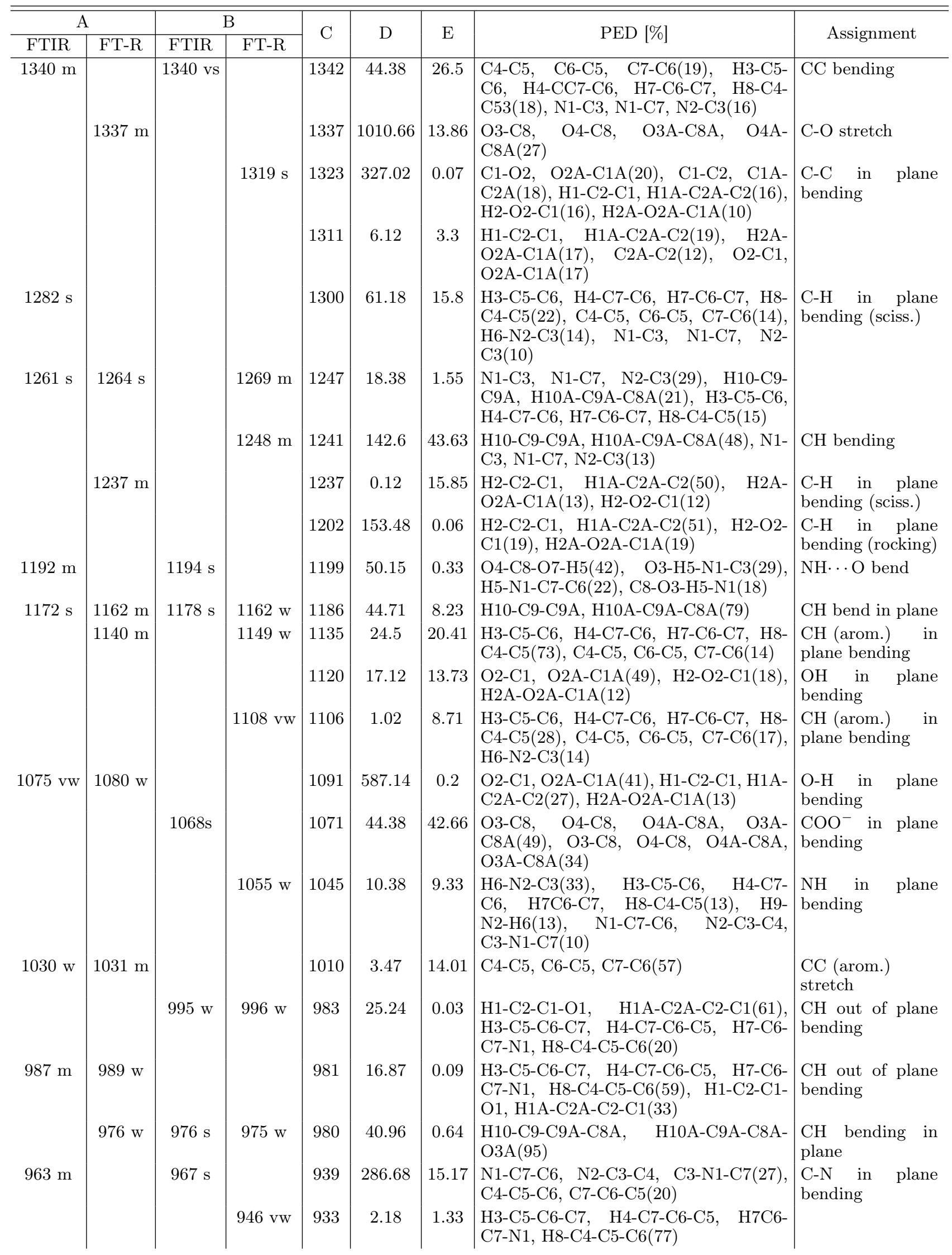


TABLE V (cont.)

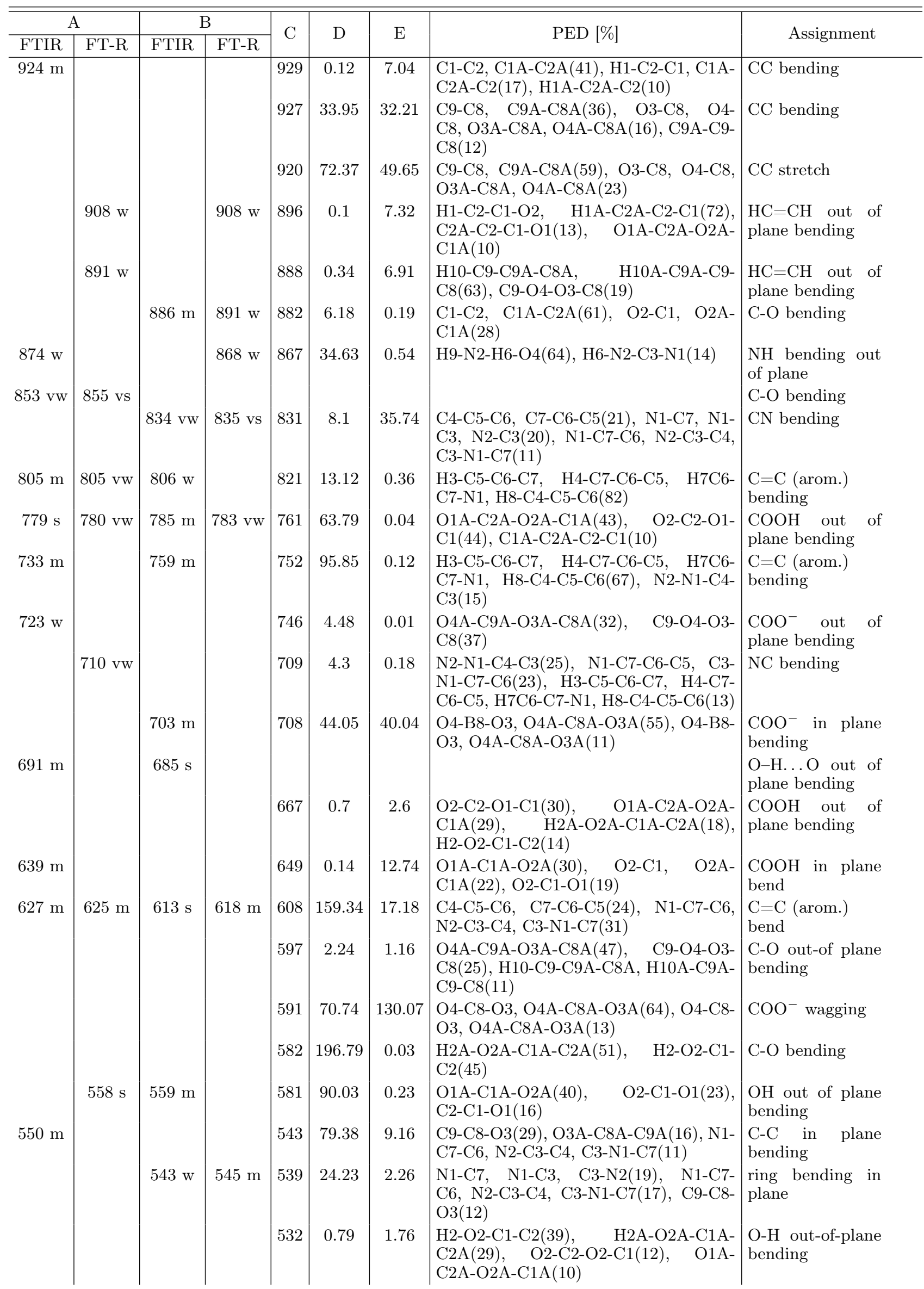


TABLE V (cont.)

\begin{tabular}{|c|c|c|c|c|c|c|c|c|}
\hline \multicolumn{2}{|c|}{$\mathrm{A}$} & \multicolumn{2}{|c|}{$\mathrm{B}$} & \multirow{2}{*}{$\mathrm{C}$} & \multirow{2}{*}{$\mathrm{D}$} & \multirow{2}{*}{$\mathrm{E}$} & \multirow{2}{*}{$\operatorname{PED}[\%]$} & \multirow{2}{*}{ Assignment } \\
\hline FTIR & FT-R & FTIR & FT-R & & & & & \\
\hline \multirow[t]{2}{*}{$525 \mathrm{~m}$} & & & & 523 & 48.55 & 0.12 & $\begin{array}{l}\text { O2A-C1A-C2A(34), } \mathrm{C} 2-\mathrm{C} 1-\mathrm{O} 1(21), \\
\mathrm{O} 2-\mathrm{C} 1-\mathrm{O} 1(18), \mathrm{C} 2 \mathrm{~A}-\mathrm{C} 2-\mathrm{C} 1(10)\end{array}$ & $\begin{array}{l}\mathrm{C}-\mathrm{C} \text { in plane } \\
\text { bending }\end{array}$ \\
\hline & & $510 \mathrm{w}$ & & 511 & 28.51 & 0.03 & $\begin{array}{l}\text { N1-C7-C6-C5(27), } \\
\text { N2-N1-C4-C3(16) }\end{array}$ & $\begin{array}{l}\text { ring out-of-plane } \\
\text { bending }\end{array}$ \\
\hline \multirow[t]{2}{*}{$433 \mathrm{~m}$} & $434 \mathrm{~m}$ & $434 \mathrm{w}$ & & 419 & 29.37 & 3.61 & N1-C7-C6(24), O3A-C8A-C9A(16) & $\begin{array}{l}\mathrm{NH}_{2} \text { in plane } \\
\text { bending }\end{array}$ \\
\hline & & & & 407 & 36.97 & 6.31 & $\begin{array}{l}\text { O3A-C8A-C9A(20), C8-C9(13), N1-C7- } \\
\text { C6(11), C9-C8-O3(10) }\end{array}$ & $\mathrm{COO}^{-}$bending \\
\hline \multirow[t]{4}{*}{$392 \mathrm{vw}$} & $396 \mathrm{vw}$ & & $391 \mathrm{w}$ & 393 & 1.04 & 0.64 & C4-C5-C6-C7(53), N1-C7-C6-C5(38) & \\
\hline & & & & 374 & 98.69 & 0.49 & $\mathrm{H} 6-\mathrm{N} 2-\mathrm{C} 3-\mathrm{N} 1(30), \mathrm{C} 4-\mathrm{C} 5-\mathrm{C} 6-\mathrm{C} 7(18)$ & $\begin{array}{l}\mathrm{C}-\mathrm{N} \text { out-of-plane } \\
\text { bending }\end{array}$ \\
\hline & & & & 355 & 0.33 & 1.2 & $\begin{array}{l}\text { O2A-C1A-O1A(33), O2-C1-O1(19), } \\
\text { C2-C1-O1(18), C1-C2(16) }\end{array}$ & \\
\hline & $290 \mathrm{vw}$ & & $289 \mathrm{w}$ & 289 & 45 & 8.58 & $\begin{array}{l}\text { C9A-C9-C } 8(24), \text { C8-O3-H5(14), O3A- } \\
\text { C8A-C9A(11) }\end{array}$ & \\
\hline $241 \mathrm{~m}$ & & & & 261 & 0.12 & 3.26 & $\begin{array}{l}\text { C1-C2(18), C2A-C2-C1(23), C2-C1- } \\
\text { O1(17), C1A-C2A-C2(22) }\end{array}$ & \\
\hline $195 \mathrm{~m}$ & & & & 198 & 0.67 & 0.37 & $\begin{array}{l}\text { N1-C7-C6-C5(38), } \\
\text { N2-N1-C4-C3(10) }\end{array}$ & lattice vibrations \\
\hline \multirow[t]{4}{*}{$182 \mathrm{~m}$} & & & & 191 & 64.29 & 1.3 & O3-H5(38), C9A-C9-C8(14) & lattice vibrations \\
\hline & & & & 153 & 5.75 & 0.22 & $\begin{array}{l}\text { C8A-C9A-C9-C8(66), O4A-C9A-O3A- } \\
\text { C8A(10) }\end{array}$ & lattice vibrations \\
\hline & & & & 147 & 10.82 & 1.88 & $\begin{array}{l}\text { C8-O3-H5(24), C8A-C9A-C9(33), O3A- } \\
\text { C8A-C9A(12) }\end{array}$ & lattice vibrations \\
\hline & & & & 139 & 0.04 & 0.06 & $\mathrm{C} 1 \mathrm{~A}-\mathrm{C} 2 \mathrm{~A}-\mathrm{C} 2-\mathrm{C} 1(74)$ & lattice vibrations \\
\hline $137 \mathrm{w}$ & 132 vs & & 131 vs & 135 & 0.02 & 1.06 & $\begin{array}{l}\mathrm{O} 2 \mathrm{~A}-\mathrm{C} 1 \mathrm{~A}-\mathrm{C} 2 \mathrm{~A}-\mathrm{C} 2(44), \quad \mathrm{C} 2 \mathrm{~A}-\mathrm{C} 2-\mathrm{C} 1- \\
\mathrm{O} 1(27), \mathrm{C} 1 \mathrm{~A}-\mathrm{C} 2 \mathrm{~A}-\mathrm{C} 2-\mathrm{C} 1(12)\end{array}$ & \\
\hline \multirow[t]{3}{*}{$122 \mathrm{w}$} & & & & 123 & 2.8 & 0.03 & C2A-C2-C1(38), C2-C1-O1(10) & lattice vibrations \\
\hline & & & & 115 & 1.15 & 0.52 & C9A-C9-C8-O4(54), C4-C5-C6-C7(13) & lattice vibrations \\
\hline & $107 \mathrm{vs}$ & & 104 vs & 102 & 13.64 & 3.01 & $\begin{array}{l}\mathrm{H} 5-\mathrm{N} 1-\mathrm{C} 7(34), \quad \mathrm{O} 3-\mathrm{H} 5-\mathrm{N} 1(27), \mathrm{H} 5- \\
\mathrm{O} 3(12), \mathrm{C} 8-\mathrm{O} 3-\mathrm{H} 5(11)\end{array}$ & lattice vibrations \\
\hline $99 \mathrm{w}$ & $87 \mathrm{~s}$ & & $85 \mathrm{~s}$ & 83 & 0.85 & 5.22 & $\begin{array}{l}\text { H5-N1-C7-C6(32), O3A-C8A-C9A- } \\
\text { C9(12) }\end{array}$ & lattice vibrations \\
\hline
\end{tabular}

\subsection{Fumarate dianion and fumaric acid vibrations}

The 2APF-F crystal consists of both dianionic and neutral molecule of fumaric acid. $\mathrm{C}-\mathrm{H}$ stretching vibrations are observed in the region $3102-3060 \mathrm{~cm}^{-1}$. The $\mathrm{CH}$ stretching vibrations in the calculated spectrum are observed at $3073,3069,3058$ and $3054 \mathrm{~cm}^{-1}$. In the experimental IR and Raman spectra this band occurs at 3055 and $3056 \mathrm{~cm}^{-1}$ with medium and strong intensity respectively. The $\mathrm{C}=\mathrm{C}$ stretching vibrations are observed in the region $1645-1530 \mathrm{~cm}^{-1}$. The stretching $\mathrm{C}=\mathrm{C}$ vibrations are seen at $1638 \mathrm{~cm}^{-1}$ for IR and $1636 \mathrm{~cm}^{-1}$ for the Raman spectrum. Theoretically this vibration is calculated at $1629 \mathrm{~cm}^{-1}$ with strong intensity. The band at $1162 \mathrm{~cm}^{-1}$ with medium intensity in the Raman is assigned to $\mathrm{CH}$ in plane bending vibrations. The corresponding IR counterpart lies at $1172 \mathrm{~cm}^{-1}$ with strong intensity. Theoretically this peak is calculated at $1186 \mathrm{~cm}^{-1}$. The band at $1411 \mathrm{~cm}^{-1}$ in the theoretical spectrum can be assign to $\mathrm{H}-\mathrm{C}$ bending vibration. The theoretically calculated $\mathrm{OH}$ stretching mode for free (not bonding) carboxylic group is at $3609 \mathrm{~cm}^{-1}$. The experimental value for this mode is at $2600 \mathrm{~cm}^{-1}$ in IR spectrum and not observed in the Raman spectrum. The stretching $\mathrm{C}=\mathrm{O}$ band is observed in IR and the Raman spectra at $1700 \mathrm{~cm}^{-1}$ with their calculated values at 1728 and $1708 \mathrm{~cm}^{-1}$, respectively. The bands corresponding to $\mathrm{C}-\mathrm{O}$ stretching mode appear at $1368 \mathrm{~cm}^{-1}$ in IR spectrum and $1337 \mathrm{~cm}^{-1}$ (very strong) for theoretical Raman spectra. The $\mathrm{C}-\mathrm{O}$ bending bands are observed at IR and Raman spectra at $853 \mathrm{~cm}^{-1}$. Calculated wavenumber of this vibration is at $882 \mathrm{~cm}^{-1}$. The Raman band at $558 \mathrm{~cm}^{-1}$ with the calculated value at $581 \mathrm{~cm}^{-1}$ comes from out of plane bending vibration of $\mathrm{OH}$ group. The asymmetric and symmetric stretching modes of $\mathrm{COO}^{-}$ group are respectively observed at 1492 and $1382 \mathrm{~cm}^{-1}$. Their calculated counterparts are at 1502 (asymmetric) and $1487 \mathrm{~cm}^{-1}$ (symmetric). The bending modes of $\mathrm{COO}^{-}$group are not observed in experimental spectra, but are visible on calculated spectrum at 708,591 , and $407 \mathrm{~cm}^{-1}$. 


\subsection{2-aminopyridine vibrations}

Vibrations of 2-aminopyridine cation can be divided into vibrations of $\mathrm{NH}_{2}$ group, $\mathrm{NH}$ stretching and bending vibrations and vibrations of the aromatic ring. Both amino groups are involved in creation of hydrogen bonds with fumarate dianion. The $\mathrm{NH}_{2}$ groups in the aminopyridine are classified to asymmetric stretching, symmetric stretching, in-plane and out-of plane bending mode of vibrations. The calculated frequencies of $\mathrm{NH}_{2}$ stretching (respectively asymmetrical and symmetrical) vibrations are lying at 3532 and $2860 \mathrm{~cm}^{-1}$. The band observed at $1643 \mathrm{~cm}^{-1}$ in theoretical IR spectra is assigned to $\mathrm{NH}_{2}$ in-plane bending vibration and in the experimental spectrum this peak is observed at $1550 \mathrm{~cm}^{-1}$ with strong intensity. The $\mathrm{NH}_{2}$ in plane rocking modes are observed at $430 \mathrm{~cm}^{-1}$ in IR and Raman spectra, and calculated at $419 \mathrm{~cm}^{-1}$. The wagging $\mathrm{NH}_{2}$ bands are observed at $733 \mathrm{~cm}^{-1}$ in IR spectra, at $752 \mathrm{~cm}^{-1}$ in calculated spectra and in the Raman spectra are not observed. Stretching vibration of $\mathrm{NH}$ group is observed at $1900 \mathrm{~cm}^{-1}$ and because of N1-H5. . O 3 hydrogen bond the band is broad. The band corresponding to $\mathrm{C}-\mathrm{N}$ stretching vibrations is calculated at $1695 \mathrm{~cm}^{-1}$. Experimentally this peak occurs at $1675 \mathrm{~cm}^{-1}$ in the IR spectra and at $1660 \mathrm{~cm}^{-1}$ in the Raman spectra. The bands from $\mathrm{C}-\mathrm{N}$ bending vibrations are observed at $550 \mathrm{~cm}^{-1}$ (in plane bending) and at $374 \mathrm{~cm}^{-1}$ (out of plane). The ring out of plane $\mathrm{C}-\mathrm{N}$ vibrations can be seen at $392 \mathrm{~cm}^{-1}$ in IR spectrum and at $396 \mathrm{~cm}^{-1}$ in Raman spectrum. Calculated counterparts are at 511 and $393 \mathrm{~cm}^{-1}$.

\subsection{H-bonds vibrations}

In the title crystal are five hydrogen bonds of $\mathrm{N}$ H... O, O-H. . O and $\mathrm{C}-\mathrm{H} . . \mathrm{O}$ type. The $\mathrm{N}-\mathrm{H}$... O types cover the range $2.77-2.94 \AA$, the O-H. . O hydrogen bond is the strongest one in the crystal and the distance between donor and acceptor is equal to $2.61 \AA$. The weakest hydrogen bond in the crystal is $\mathrm{C}-\mathrm{H}$... O type $(3.18 \AA)$. The two broad bands from $\mathrm{O}-\mathrm{H}$ and $\mathrm{N}-\mathrm{H}$ stretching vibrations are observed in IR spectra in the range $3500-2000 \mathrm{~cm}^{-1}$. In the optimized geometry are only two hydrogen bonds of N-H. . . O type. The band derived from $\mathrm{O}-\mathrm{H}$. . . O stretching vibration in the IR spectrum is at $2600 \mathrm{~cm}^{-1}$ and is not observed in the theoretical spectrum. The $\mathrm{N}-\mathrm{H}$. . . O stretching vibration occurs at $1900 \mathrm{~cm}^{-1}$ with strong intensity. Upon deuteration, these bands are moved to 1950 and about $1600 \mathrm{~cm}^{-1}$, respectively. The $\mathrm{N}-\mathrm{H}$... O out of plane bending vibration occurs at $1190 \mathrm{~cm}^{-1}$. The IR band at $691 \mathrm{~cm}^{-1}$ is assigned to $\mathrm{O}-\mathrm{H}$. . . O out of plane bending vibrations, and its counterpart at deuterated analogue spectrum is at $685 \mathrm{~cm}^{-1}$.

\subsection{Frontier molecular orbital analysis}

Frontier molecular orbital (HOMO-LUMO) analysis has been done to determine the molecular reactivity and the ability of a molecule to absorb light. It also plays an important role in electrical, optical properties, UVVis spectra and chemical reactions [23-26]. Also, the HOMO-LUMO energy gap is used to determine molecular electrical transport properties [25]. The calculated HOMO-LUMO for 2APF-F by B3LYP/6-311G(d,p) basis set is shown in Fig. 6. It is seen from Fig. 6 that electrons for HOMO are delocalized mainly on the 2aminopyridinium ring and on the carboxylate group (this group is hydrogen bonded with cation). However for the LUMO electrons are delocalized on the whole fumaric acid molecule. For the LUMO+1 electrons are delocalized practically on the whole molecule of bis $(2-$ aminopyridinium) fumarate fumaric acid 1:1 and for the HOMO-1 electrons are delocalized on the anion and partly on the nitrogen of 2-aminopyridinium cation. Energy gap between HOMO and LUMO equals $3.53 \mathrm{eV}$ which show that the charge transfer occurs in $2 \mathrm{APF}$ $\mathrm{F}$ molecule [26]. The chemical reactivity descriptors of molecules such as chemical potential $\mu$, electronegativity $\chi$, chemical hardness $\eta$ and softness $S$ are defined as follows:

$$
\begin{array}{ll}
\eta=\frac{(I-A)}{2}, & S=\frac{1}{2 \eta} \\
\chi=\frac{(I+A)}{2}, & \mu=-\frac{(I+A)}{2},
\end{array}
$$

where $I$ and $A$ are the ionization potential and electron affinity of the molecules, respectively. The ionization energy and electron affinity can be expressed through $\mathrm{HOMO}$ and LUMO energies as $I=-E_{\mathrm{HOMO}}$ and $A=-E_{\mathrm{LUMO}}$. It is widely known that chemical hardness and softness are useful properties to measure the molecular stability and reactivity. A soft molecule has a small HOMO-LUMO gap and is more reactive than hard molecule which has a bigger energy gap.

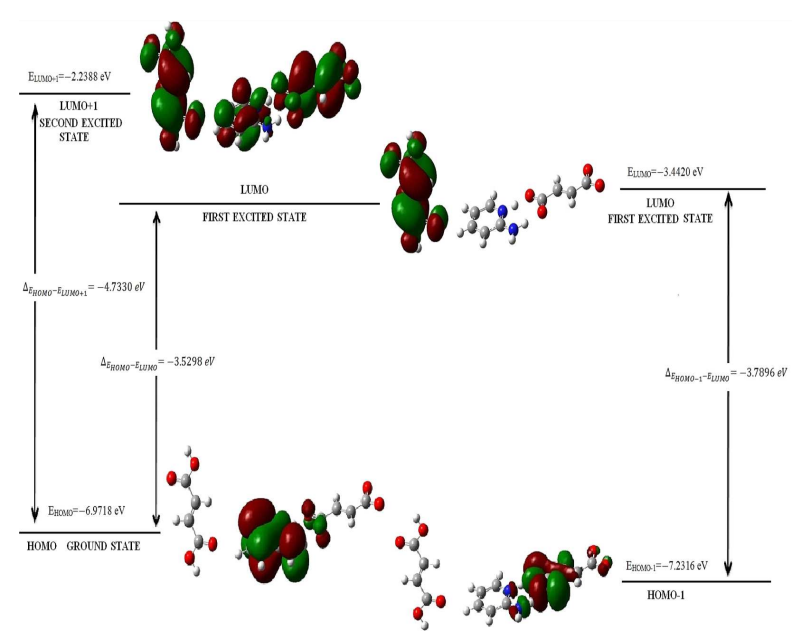

Fig. 6. Frontier orbital analysis of 2APF-F.

In order to study the chemical reactivity and stability of 2APF-F, the chemical hardness, softness, electronegativity and chemical potential have been calculated and the results are presented in Table VI. To investigate the 
TABLE VI

The calculated frontier orbital energies, ionization potential, electron affinity, hardness, softness, electronegativity, chemical potential for $2 \mathrm{APF}-\mathrm{F}$.

\begin{tabular}{c|c|c|c|c}
\hline \hline & \multicolumn{2}{|c|}{ Gas phase $(\varepsilon=1)$} & \multicolumn{2}{c}{ Water $(\varepsilon=78.39)$} \\
\hline & $\alpha$ & $\beta$ & $\alpha$ & $\beta$ \\
\hline$E_{\text {HOMO }}$ & -6.97 & -6.97 & -6.77 & -6.77 \\
$E_{\text {LUMO }}$ & -3.44 & -4.73 & -2.95 & -5.42 \\
$I$ & 6.97 & 6.97 & 6.77 & 6.77 \\
$A$ & 3.44 & 4.73 & 2.95 & 5.42 \\
$\eta$ & 1.76 & 1.11 & 1.91 & 0.67 \\
$S$ & 0.28 & 0.44 & 0.26 & 0.73 \\
$\chi$ & 5.20 & 5.85 & 4.86 & 6.09 \\
$\mu$ & -5.20 & -5.85 & -4.86 & -6.09
\end{tabular}

solvent effect for the chemical reactivity descriptors based on B3LYP/6-311 ++ G(d,p) model and PCM method, one kind of solvent is used - water $(\varepsilon=78.39)$.

According to Table VI, energy gap between HOMO and LUMO orbitals for the dissolved particle is bigger than in the gas phase and increases from $3.53 \mathrm{eV}$ to $3.82 \mathrm{eV}$. The chemical hardness increase and the softness decrease in the solution phase. The molecule in the gas phase is more reactive than in solution phase.

\subsection{Determination of molecular electrostatic potential}

The possible sites for electrophilic and nucleophilic reactions as well as hydrogen bonding interactions [27, 28] are determined by the molecular electrostatic potential (MEP). The MEP is a plot of electrostatic potential surface, i.e. plot of electrostatic potential mapped on the constant electron density surface. To predict reactive sites for nucleophilic and electrophilic attack for $2 \mathrm{APF}-\mathrm{F}$ the MEP at the B3LYP $/ 6-311++\mathrm{G}(\mathrm{d}, \mathrm{p})$ optimized geometry was calculated. Figure 7 shows the $3 \mathrm{D}$ plot of

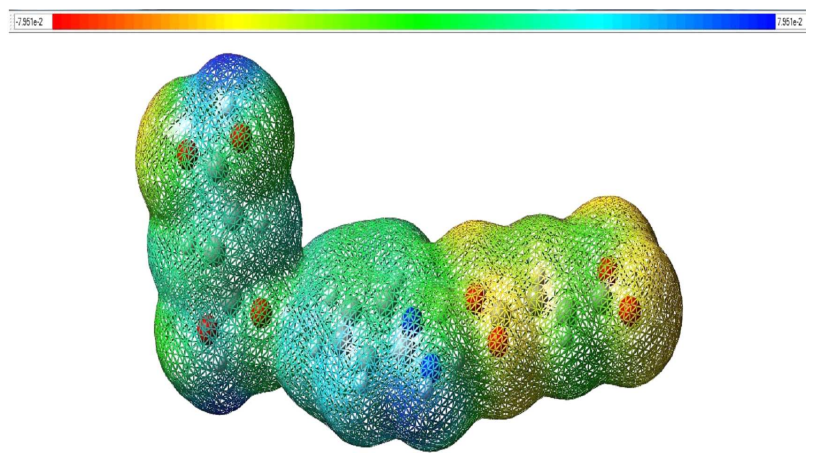

Fig. 7. Molecular electrostatic potential map of $2 \mathrm{APF}-\mathrm{F}$.

2APF-F molecule with uniform total energy distribution. The electrostatic potential of the molecule is in the range $-7.951 \times 10^{-2}$ (deep red) to $+7.951 \times 10^{-2}$ (deep blue) where blue color indicates the strongest attraction and red indicates the strongest repulsion. The MEP map shows that the negative potential sites are on the oxygen atoms and positive potential sites are around hydrogen atoms from carboxylic group. These sites give information concerning the region from where the compound can have the intermolecular interaction.

\subsection{NBO analysis}

To investigate intermolecular interactions, the NBO analysis was carried out for the title compound. For each donor $\mathrm{NBO}(i)$ and acceptor $(j)$, the stabilization energy $E^{(2)}$ associated to electron delocalization between donor and acceptor is estimated as

$$
E^{(2)}=-q_{i} \frac{F_{i j}^{2}}{\varepsilon_{i}-\varepsilon_{j}},
$$

where $q_{i}$ is the donor orbital occupancy, $\varepsilon_{i}, \varepsilon_{j}$ are diagonal elements (orbital energies) and $F_{i j}$ is the off-diagonal NBO Fock matrix element. The results of second-order perturbation theory analysis are collected in Table VII.

TABLE VII

Second-order perturbation theory analysis of the Fock matrix in NBO, calculated at B3LYP/6-311++G(d,p).

\begin{tabular}{|c|c|c|c|c|}
\hline Donor orb. $i$ & Acceptor orb. $j$ & $E^{(2)}$ & $\varepsilon_{j}-\varepsilon_{i}$ & $F_{i j}$ \\
\hline $\mathrm{LP}(1) \mathrm{O} 27$ & $\mathrm{BD}^{*}(1) \mathrm{O} 52-\mathrm{H} 56$ & 5.51 & 1.02 & 0.09 \\
\hline $\mathrm{LP}(2) \mathrm{O} 27$ & $\mathrm{BD}^{*}(1) \mathrm{O} 52-\mathrm{H} 56$ & 15.21 & 0.68 & 0.13 \\
\hline $\mathrm{LP}(3) \mathrm{O} 27$ & $\mathrm{BD}^{*}(1) \mathrm{O} 52-\mathrm{H} 56$ & 1.06 & 0.63 & 0.03 \\
\hline $\mathrm{LP}(1) \mathrm{O} 27$ & $\mathrm{BD}^{*}(1) \mathrm{N} 13-\mathrm{H} 22$ & 4.60 & 1.26 & 0.96 \\
\hline $\mathrm{LP}(2) \mathrm{O} 27$ & $\mathrm{BD}^{*}(1) \mathrm{N} 13-\mathrm{H} 22$ & 1.84 & 0.91 & 0.05 \\
\hline $\mathrm{LP}(3) \mathrm{O} 27$ & $\mathrm{BD}^{*}(1) \mathrm{N} 13-\mathrm{H} 22$ & 0.10 & 0.86 & 0.01 \\
\hline LP (1) O28 & $\mathrm{BD}^{*}(1) \mathrm{N} 14-\mathrm{H} 23$ & 1.02 & 1.36 & 0.04 \\
\hline LP (2) O28 & $\mathrm{BD}^{*}(1) \mathrm{N} 14-\mathrm{H} 23$ & 2.54 & 0.94 & 0.06 \\
\hline LP (3) O 28 & $\mathrm{BD}^{*}(1) \mathrm{N} 14-\mathrm{H} 23$ & 0.43 & 0.93 & 0.02 \\
\hline LP (1) O28 & $\mathrm{BD}^{*}(1) \mathrm{N} 38-\mathrm{H} 50$ & 0.93 & 1.24 & 0.04 \\
\hline $\mathrm{LP}(2) \mathrm{O} 28$ & $\mathrm{BD}^{*}(1) \mathrm{N} 38-\mathrm{H} 50$ & 1.09 & 0.82 & 0.03 \\
\hline LP (3) O28 & $\mathrm{BD}^{*}(1) \mathrm{N} 38-\mathrm{H} 50$ & 1.94 & 0.81 & 0.04 \\
\hline LP (1) O51 & $\mathrm{BD}^{*}(1) \mathrm{C} 19-\mathrm{H} 21$ & 1.20 & 1.23 & 0.04 \\
\hline LP (2) O51 & $\mathrm{BD}^{*}(1) \mathrm{C} 19-\mathrm{H} 21$ & 0.49 & 0.80 & 0.02 \\
\hline$E^{(2)}-\epsilon$ & $\begin{array}{l}\text { ergy of hyper } \\
\text { oll: } \varepsilon_{i}-\varepsilon_{i}\end{array}$ & conje & ative & $\begin{array}{l}\text { terac- } \\
\text { [a.u.] } \\
\text { s; } F_{i j} \\
\text { NBO }\end{array}$ \\
\hline
\end{tabular}

It is seen that the biggest contribution to the stabilization energy of the system is due to $\mathrm{O} 2^{a}-\mathrm{H} 2^{a} \ldots \mathrm{O} 3$ hydrogen bond. The stabilization energy between lone electrons pair on the O27 oxygen atom of the carboxylate group and the antibonding orbital $\sigma(\mathrm{O} 52-\mathrm{H} 56)$ equals $21.78 \mathrm{kcal} / \mathrm{mol}[29,30]$. The second according to the bond strength is the $\mathrm{N} 1-\mathrm{H} 5 \ldots$ O 3 hydrogen bond with the stabilization energy equals $6.54 \mathrm{kcal} / \mathrm{mol}$. The remaining two hydrogen bonds of $\mathrm{N}-\mathrm{H}$... O type are weaker, the interaction energy between lone pairs $n(\mathrm{O} 28)$ and antibonding orbital $\sigma(\mathrm{N} 14-\mathrm{H} 23)$ is equal to $3.99 \mathrm{kcal} / \mathrm{mol}$, while the stabilization energy for $\mathrm{N} 2$ $\mathrm{H} 9 . . \mathrm{O} 4^{b}$ hydrogen bond equals $3.96 \mathrm{kcal} / \mathrm{mol}$. As it 
could be expected, on the basis of crystallographic data, the weakest bond in the studied system is unconventional hydrogen bond of $\mathrm{C}-\mathrm{H}$. . . O type between $\pi$-electrons of 2-aminopyridinium ring and oxygen atom lone pair of neutral molecule of fumaric acid. The stabilization energy of this bond equals $1.69 \mathrm{kcal} / \mathrm{mol}$ and corresponds to weak hydrogen bond. Crystallographic data and the results of NBO calculations are in good agreement. It is worthwhile mentioned that the results of theoretical calculations could not reflect the current situation in real crystal as for simulations one can choose several neighboring molecules only which are additionally located at the vacuum. Therefore the effects originating from crystal packing phenomena, i.e. intermolecular interactions, are neglected.

\subsection{NLO properties}

It is well known that the importance of polarizability and hyperpolarizability of a molecular system is dependent on the electronic communication of two different parts of a molecule. Nonlinear activity of any materials provides the key functions from applications point of views for frequency shifting, optical modulation, optical switching etc. for developing technologies in the area of communication, optical processing and interconnection $[31,32]$. The dipole moment $\mu$, polarizability $\alpha$ and the first hyperpolarizability $\beta$ were calculated with the level of B3LYP $/ 6-311++\mathrm{G}(\mathrm{d}, \mathrm{p})$ basis set on the basis of the finite field approach. The complete equations for calculating the magnitude of total static dipole moment $\mu$, the mean polarizability $\alpha_{0}$, the anisotropy of the polarizability $\Delta \alpha$ and mean first polarizability $\beta_{0}$, using the $x, y, z$ components are obtained from the Gaussian output as follows:

$$
\begin{aligned}
& \mu_{\mathrm{tot}}=\left(\mu_{x}^{2}+\mu_{y}^{2}+\mu_{z}^{2}\right)^{1 / 2}, \quad \alpha_{\mathrm{tot}}=\frac{\alpha_{x} x+\alpha_{y} y+\alpha_{z} z}{3}, \\
& \beta_{\mathrm{tot}}=\left(\left(\beta_{x x x}+\beta_{x y y}+\beta_{x z z}\right)^{2}+\left(\beta_{y y y}+\beta_{y z z}+\beta_{y x x}\right)^{2}\right. \\
& \left.\quad+\left(\beta_{z z z}+\beta_{z x x}+\beta_{z y y}\right)^{2}\right)^{1 / 2} .
\end{aligned}
$$

\section{TABLE VIII}

Calculated dipole moments $-\mu$, polarizability $-\alpha$ and the first hyperpolarizability $-\beta$ components, all [a.u.], for the title compound.

\begin{tabular}{rrrr}
\hline \hline$\mu_{x}$ & -4.84 & $\beta_{x x x}$ & 1156.63 \\
$\mu_{y}$ & -1.42 & $\beta_{x x y}$ & 537.93 \\
$\mu_{z}$ & 0.70 & $\beta_{x y y}$ & 144.33 \\
$\mu_{\text {tot }}$ & 5.10 & $\beta_{y y y}$ & 25.02 \\
$\alpha_{x x}$ & 294.44 & $\beta_{x x z}$ & -348.14 \\
$\alpha_{x y}$ & 8.33 & $\beta_{x y z}$ & -86.43 \\
$\alpha_{y y}$ & 180.54 & $\beta_{y y z}$ & -39.11 \\
$\alpha_{x z}$ & 25.27 & $\beta_{x z z}$ & -9.76 \\
$\alpha_{y z}$ & -13.59 & $\beta_{y z z}$ & 6.28 \\
$\alpha_{z z}$ & 172.14 & $\beta_{z z z}$ & -26.96 \\
$\alpha_{\text {tot }}$ & 215.71 & $\beta_{\text {tot }}$ & 1470.65
\end{tabular}

The calculated dipole moment, the polarizability and first hyperpolarizability are listed in Table VIII. Since the values of the polarizability $\left(\alpha_{\text {tot }}\right)$ and hyperpolarizability $\left(\beta_{\text {tot }}\right)$ of the Gaussian 03 output are reported in atomic units (a.u.), the calculated values have been converted into electrostatic units (esu) $(\alpha: 1$ a.u. $=$ $0.148 \times 10^{-24}$ esu and $\beta$ : 1 a.u. $\left.=8.639 \times 10^{-33} \mathrm{esu}\right)$. The calculated values of electric dipole moment, polarizability and the first hyperpolarizability of 2APF-F are 5.1003 D, $31.9252 \AA^{3}$ and $1.27 \times 10^{-29} \mathrm{~cm}^{5} \mathrm{esu}^{-1}$. The large value of first hyperpolarizability, which is more than 16 times greater than urea $\left(0.78 \times 10^{-30} \mathrm{~cm}^{5} \mathrm{esu}^{-1}\right)$ may be associated with the large number of $\pi$ conjugated bonds and intramolecular hydrogen bonds [33].

\subsection{Thermodynamic properties}

On the basis of vibrational analysis and statistical thermodynamics, the standard thermodynamic functions: constant volume heat capacity $C_{v}$, entropy $S$, and enthalpy $H$ were obtained at B3LYP $/ 6-311++\mathrm{G}(\mathrm{d}, \mathrm{p})$ level and listed in Table IX. Table IX shows that the standard heat capacities, entropies, and enthalpies increase at any temperature from 200.00 to $500.00 \mathrm{~K}$, because the intensities of molecular vibration increase with the increasing temperature.

TABLE IX

Thermodynamic properties at different temperatures at B3LYP $/ 6-311++\mathrm{G}(\mathrm{d}, \mathrm{p})$.

\begin{tabular}{c|c|c|c}
\hline \hline$T[\mathrm{~K}]$ & $C_{v}[\mathrm{cal} /(\mathrm{mol} \mathrm{K})]$ & $S[\mathrm{cal} /(\mathrm{mol} \mathrm{K})]$ & $H[\mathrm{kcal} / \mathrm{mol}]$ \\
\hline 200 & 63.04 & 167.61 & 169.88 \\
250 & 73.44 & 183.21 & 173.40 \\
298.15 & 83.50 & 197.38 & 177.27 \\
300 & 83.88 & 197.91 & 177.43 \\
350 & 93.94 & 211.91 & 181.98 \\
400 & 103.33 & 225.34 & 187.01 \\
450 & 111.91 & 238.25 & 192.49 \\
500 & 119.66 & 250.66 & 198.39
\end{tabular}

The correlations between these thermodynamic properties and temperatures $T$ are as follows:

$$
\begin{aligned}
& C_{p, m}^{0}=13.596+0.268 T-10^{-4} T^{2}\left(R^{2}=0.9999\right), \\
& S_{m}^{0}=100.02+0.3636 T-10^{-4} T^{2}\left(R^{2}=1\right), \\
& H_{m}^{0}=160.44+0.279 T-10^{-4} T^{2}\left(R^{2}=1\right) .
\end{aligned}
$$

\section{Conclusion}

Optimized geometry of bis(2-aminopyridinium) fumarate - fumaric acid (1:1) [2APF-F] has been obtained. Comparison of the crystal structure and the theoretically calculated geometry show small differences in bond lengths and atomic angles values. In spite of the differences observed in the geometric parameters, the general agreement is good and the calculated results support the solid-state structure. Several infrared and Raman modes have been identified and assigned for the title 
crystal. The theoretical and observed frequencies have been compared and several stretching and deformation modes confirm the presence of intermolecular hydrogen bonding in the title crystal. The present work is, therefore, an attempt to present a critical review of the data on which infra-red spectral correlations are based indicating the classes of compounds which have been studied in each case the factors which can influence the frequencies or intensities of the characteristic bands. The TD-DFT calculations on the molecule provided deep insight into their electronic structure and properties. The HOMO-LUMO energy gap supports the charge transfer interaction within the molecule. NBO charges clearly show that the hydrogen atoms which are involved in $\mathrm{N}$ H. . O bonds have a positive charge compared with other hydrogen atom in the molecule. The positive and negative potential sites in the molecular electrostatic potential surface confirm the existence of $\mathrm{N}-\mathrm{H}$. . . O, O-H. . O and $\mathrm{N}-\mathrm{H}$. . . N intermolecular interactions in the solid state. The large value of first hyperpolarizability suggests that the studied molecule $2 \mathrm{APF}-\mathrm{F}$ is a good candidate for higher order nonlinear optical applications.

\section{References}

[1] S. Goswami, A.K. Mahapatra, G.D. Nigam, K. Chinnakali, H. Kun Fun, I.A. Razak, Acta Crystallogr. C 55, 583 (1999).

[2] A. Ballabh, D.R. Trivedi, P. Dastidar, E. Suresh, Cryst. Eng. Commun. 4, 135 (2002).

[3] S. Dong, Y. Tao, X. Shen, Z. Pan, Acta Crystallogr. C 69, 896 (2013).

[4] M. Solich, W. Krol, K. Skirmuntt, Pol. J. Chem. 67, 433 (2013).

[5] F.C. Wang, J.G. Green, B.B. Gerhart, Anal. Chem. 68, 2477 (1996).

[6] S. Eiem-Ong, M. Spohn, N.A. Kurtzman, S. Sabatini, Kidney Int. 48, 1542 (1995).

[7] E. Castrano, P. Marzabal, F.J. Casado, A. Felipe, M. Pastor-Anglada, Clin. Sci. 92, 247 (1997).

[8] K. Tsuchiya, T. Uchida, M. Kobayashi, H. Maeda, T. Konno, H. Yamanaka, Urology 55, 495 (2000).

[9] M. Akao, K. Kuroda, Chem. Pharmaceut. Bull. 28, 2012 (1990).

[10] E.M.S. Macoas, R. Fausto, J. Lundell, M. Pettersson, L. Khriachtchev, M. Rasanen, J. Phys. Chem. A 105, 3922 (2001).

[11] S. Mohan, V. Ilangovan, Asian J. Chem. 3, 556 (1995).

[12] G. Anandha Babu, R.P. Ramasamy, P. Ramasamy, Mater. Chem. Phys. 117, 326 (2009).

[13] A. Novak, Struct. Bond. 18, 177 (1974).

[14] A.S. Davydov, Theory of Molecular Excitons, McGraw-Hill, New York 1962.
[15] Kuma Diffraction, KM4/CCD Users' Guide, Version 1.169, release April 2000, Wroclaw, Poland 2000.

[16] G.M. Sheldrick, SHELXL, Program for Crystal Structure Refinement, University of Gottingen, Germany 1993.

[17] G.M. Sheldrick, Acta Crystallogr. A 64, 112 (2008).

[18] M.J. Frisch, G.W. Trucks, H.B. Schlegel, G.E. Suzerain, M.A. Robb, J.R. Cheeseman Jr., J.A. Montgomery, T. Vreven, K.N. Kudin, J.C. Burant, J.M. Millam, S.S. Iyengar, J. Tomasi, V. Barone, B. Mennucci, M. Cossi, G. Scalmani, N. Rega, G.A. Petersson, H. Nakatsuji, M. Hada, M. Ehara, K. Toyota, R. Fukuda, J. Hasegawa, M. Ishida, T. Nakajima, Y. Honda, O. Kitao, H. Nakai, M. Klene, X. Li, J.E. Knox, H.P. Hratchian, J.B. Cross, V. Bakken, C. Adamo, J. Jaramillo, R. Gomperts, R.E. Stratmann, O. Yazyev, A.J. Austin, R. Cammi, C. Pomelli, J.W. Ochterski, P.Y. Ayala, K. Morokuma, G.A. Voth, P. Salvador, J.J. Dannenberg, V.G. Zakrzewski, S. Dapprich, A.D. Daniels, M.C. Strain, O. Farkas, D.K. Malick, A.D. Rabuck, K. Raghavachari, J.B. Foresman, J.V. Ortiz, Q. Cui, A.G. Baboul, S. Clifford, J. Cioslowski, B. Stefanov, G. Liu, A. Liashenko, P. Piskorz, I. Komaromi, R.L. Martin, D.J. Fox, T. Keith, M.A. Al-Laham, C.Y. Peng, A. Nanayakkara, M. Challacombe, P.M.W. Gill, B. Johnson, W. Chen, M.W. Wong, C. Gonzalez, J.A. Pople, Gaussian 09, Gaussian Inc., Wallingford (CT) 2003.

[19] H. Tanak, Mol. Phys. 112, 1553 (2014).

[20] M.H. Jamróz, Spectr. Acta A: Mol. Biomol. Spectr. 114, 220 (2013).

[21] E.D. Glendening, A.E. Reed, J.E. Carpenter, F. Weinhold, NBO Version 3.1.

[22] D. Michalska, R. Wysokiński, Chem. Phys. Lett. 403, 211 (2005).

[23] J. Fleming, Frontier Orbitals and Organic Chemical Reactions, Wiley, London 1976.

[24] T. Karakurt, M. Dincer, A. Cetin, M. Sekera, Spectrochim. Acta A 77, 189 (2010).

[25] K. Fukui, Science 218, 747 (1982).

[26] R.G. Pearson, J. Am. Chem. Soc. 107, 6801 (1985).

[27] H. Tanak, M.K. Marchewka, M. Drozd, Spectrochim. Acta A 105, 156 (2013).

[28] E. Scrocco, J. Tomasi, Adv. Quant. Chem. 11, 115 (1978).

[29] P.A. Wood, F.H. Allen, E. Pidcock, Cryst. Eng. Commun. 11, 1563 (2009).

[30] G.R. Desiraju, Angew. Chem. Int. Ed. 50, 52 (2011).

[31] C. Andraud, T. Brotin, C. Garcia, F. Pelle, P. Goldner, B. Bigot, A. Collet, J. Am. Chem. Soc. 116, 2094 (1994).

[32] V.M. Geskin, C. Lambert, J.L. Brédas, J. Am. Chem. Soc. 125, 15651 (2003).

[33] A.B. Ahmed, H. Feki, Y. Abid, C. Minot, Spectrochim. Acta A 75, 1315 (2010). 